\title{
Mild steel protection in acidic media using Mucuna pruriens seed extract
}

\author{
C.O. Akalezi, ${ }^{1}$ C.E. Ogukwe, ${ }^{1}$ E.A. Ejele ${ }^{2}$ and E.E. Oguzie ${ }^{1}$ \\ ${ }^{1}$ Electrochemical and Material Science Unit (EMRU), Department of Chemistry, School \\ of Sciences, Federal University of Technology Owerri, PMB 1526 Owerri, Nigeria \\ ${ }^{2}$ Department of Chemistry; School of Physical Sciences, \\ Federal University of Technology Owerri, PMB 1526 Owerri, Nigeria \\ E-mail: chrisakalezi@yahoo.com
}

\begin{abstract}
The inhibition of corrosion of mild steel in 1 molar hydrochloric acid solution $(1 \mathrm{M} \mathrm{HCl})$ by Mucuna pruriens seed extract (MPSE) was investigated by weight-loss and electrochemical techniques. A significant decrease in the corrosion rate of mild steel was observed in the presence of the investigated additive and the inhibition efficiency was found to depend on the concentration of the MPSE. The potentiodynamic polarization data indicated that this additive was of mixed type, but the anodic effect was more pronounced. Nyquist plots showed that on increasing the MPSE concentration, the charge transfer resistance increased and double layer capacitance decreased. The thermodynamic parameters of adsorption revealed a strong interaction between the MPSE constituents and the corroding metal surface. MPSE lowered the corrosion reaction by blocking the mild steel surface through chemical adsorption. The mechanism of inhibition was discussed in the light of the chemical structure of the four major components of MPSE.
\end{abstract}

Key words: Mucuna pruriens, mild steel, corrosion inhibition, hydrochloric acid.

Received: February 2, 2016. Published: April 7, 2016.

doi: $\underline{10.17675 / 2305-6894-2016-5-2-3}$

\section{Introduction}

Inhibitors are frequently used for controlling corrosion of metals and alloys in acidic media, for removing scales and rusts in metal finishing industries, cleaning of boilers and heat exchangers [1-4]. Several organic compounds have been evaluated as inhibitors for metal protection in corrosive media. The efficiency of these organic compounds have been related to the presence of polar atoms such $\mathrm{S}, \mathrm{O}$ or $\mathrm{N}$ in the molecule, heterocyclic compounds and pi-electrons [5-10]. These polar functions are usually regarded as the reaction center for the establishment of the adsorption process [11]. However, the use of such compounds is becoming increasingly unpopular arising from the toxic nature of some of these compounds. 
Current research efforts in corrosion inhibitors is directed towards the development of "green corrosion inhibitors", compounds with good inhibition efficiency but low risk of environmental pollution $[12,13]$.

Plant extracts represents an excellent alternative inhibitors as they are non-toxic, environmentally acceptable, available and cost effective [14]. Moreover, Plant extracts contain a variety of natural products such as essential oils, tannins, pigments, steroids, terpenes, flavones and flavonoids, among other well-known active substances used as corrosion inhibitors [14-16]. These compounds often present conjugated aromatic structures, long aliphatic chains bearing $\mathrm{N}, \mathrm{S}$, and $\mathrm{O}$ heteroatoms with free electron pairs available to bond with the metal surface. In most cases, they act synergistically to exhibit good efficiency regarding the corrosion protection. Various plant parts; seeds [17-19], fruits [20], leaves [21-23], flowers [24-28], and leaves [29-31] have been extracted and analyzed for their corrosion inhibition potentials.

Mucuna pruriens belongs to the family fabaceae, commonly known as cowhage plant, is the most popular drug in Ayurvedic system of medicine [32-35]. In Nigeria, the seeds of Mucuna pruriens are used as a tonic and aphrodisiac for male virility. Seeds of velvet beans are known to produce the non-protein amino acid 3-(3,4-dihydroxyphenyl)-L-alanine (L-DOPA (LDP)), a potent neurotransmitter precursor. Beside this it also contains some other amino acids, glutathione (GTT), gallic acid (GA) and $\beta$-sitosterol (BSS). Other bases isolated from the pods, seeds, leaves and roots include indole-3-alkylamines-N,Ndimethyl-tryptamine [34]. The seeds also contain oils including palmitic, stearic, oleic and linoleic acids [35]. Mucuna pruriens has not been studied for corrosion inhibition purposes. However, the synthetic version of one of the constituents, L-dopa has been studied for mild steel corrosion inhibition in aqueous $\mathrm{HCl}$ and $\mathrm{H}_{2} \mathrm{SO}_{4}$ acid solutions yielding efficiency values of 70.5 and 75.0 percent respectively [36].

The present study reports on the corrosion protection of mild steel in $\mathrm{HCl}$ acid solution in the presence of MPSE, using weight loss and electrochemical technique. Temperature effects on the value of the weight loss parameters characterizing the systems have been recorded.

\section{Experimental approach}

\subsection{Materials Preparation}

Corrosion experiments were performed on mild steel electrodes with percentage composition as follows: $\mathrm{C}(0.05)$; $\mathrm{Mn}(0.6)$; P (0.36); Si (0.31) and Fe balance. The corrosive medium was a $1 \mathrm{M} \mathrm{HCl}$ solution prepared from analytical grade reagents. Stock solutions of MPSE were prepared by boiling $50 \mathrm{~g}$ of ground seeds of MPE in $500 \mathrm{~mL}$ ethanol solution under reflux for $3 \mathrm{~h}$. The resulting solution was cooled and filtered to remove any solid material. The concentrations of the extracts are expressed as $\mathrm{g} / \mathrm{l}$. 


\subsection{Gravimetric measurements}

Gravimetric measurements were performed on mild steel electrodes of size $3 \times 3 \times 0.15 \mathrm{~cm}$ prior to each experiment the mild steel electrodes were smoothened using abrasive papers (grades 200, 600 and 1000) washed with distilled water, dried in acetone and warm air. The weights of the steel electrode were taken prior to immersion. Tests were conducted under total immersion conditions in $300 \mathrm{ml}$ of aerated test solutions kept without stirring. The test were removed after $24 \mathrm{~h}$, rinsed with double distilled water, dipped in $10 \% \mathrm{HNO}_{3}$ for 2 minutes and washed again with double distilled water; degreased with ethanol, dried in warm air and reweighed. All tests were run in triplicate and the data showed good reproducibility with standard deviation $<6.5 \times 10^{-4}$. The corrosion rates were calculated using the weight losses as follows:

$$
C_{\mathrm{R}}\left(\mathrm{mg} \mathrm{cm}^{-2} \mathrm{~h}^{-1}\right)=\frac{\Delta w}{s t},
$$

where $\Delta w$ is weight loss $(\mathrm{mg}), s$ is area of specimen $\left(\mathrm{cm}^{2}\right)$ and $t$, the immersion time (hours). The efficiency of inhibition (IE\%) was calculated as follows:

$$
I E \%=\frac{w_{0}-w_{1}}{w_{0}} \times 100,
$$

where $w_{0}$ and $w_{1}$ are the weight loss in absence and presence of inhibitor, respectively.

\subsection{Electrochemical measurements}

Electrochemical tests were accomplished in a Galvanostat/Potentiostat (VERSASTAT 400) Corrosion System, with V3 Studio software using a traditional three-electrode cell consisting of a graphite rod as counter electrode, saturated calomel electrode as reference electrode, and the mild steel sample as working electrode. The mild steel samples were embedded in epoxy resin so that only $1.0 \mathrm{~cm}^{2}$ area was exposed to the electrolyte. The electrolyte was $1 \mathrm{M} \mathrm{HCl}$ solution containing various concentrations of the extract. The electrode potential was allowed to stabilize for 60 minutes before starting the measurements. All experiments were conducted at $303 \mathrm{~K}$.

The electrochemical impedance measurement spectroscopy (EIS) tests were carried out at open circuit potential (OCP) by applying $5 \mathrm{mV}$ sinusoidal voltage in the frequency range of $100 \mathrm{kHz}$ to $10 \mathrm{mHz}$. Tafel polarization curves were obtained in the potential range $\pm 250 \mathrm{mV}$ versus corrosion potential $\left(E_{\text {corr }}\right)$ at a scan rate of $0.33 \mathrm{mV} \mathrm{s}^{-1}$. The linear Tafel segment of anodic and cathodic curves was extrapolated to corrosion potential to obtain corrosion current densities $\left(i_{\text {corr }}\right)$. The inhibition efficiency $I E \%$ values were obtained from the measured $i_{\text {corr }}$ using the equation:

$$
I E_{i} \%=\left(1-\frac{i_{\text {corr,inh }}}{i_{\text {corr,bl }}}\right) \times 100,
$$


where $\left(i_{\text {corr,bl }}\right)$ and $\left(i_{\text {corr,inh }}\right)$ are the corrosion current densities, measured in solution without and with inhibitor. The charge transfer resistance values were obtained from the diameters of the semi circles of the Nyquist plots. The inhibition efficiency of the inhibitor has been found out from the charge transfer resistance values using the equation:

$$
I E_{\mathrm{R}} \%=\left(\frac{R_{\mathrm{ct}(\mathrm{inh})}-R_{\mathrm{ctbl}}}{R_{\mathrm{ct}(\mathrm{inh})}}\right) \times 100,
$$

where $\left(R_{\mathrm{ct}, \mathrm{bl}}\right)$ and $\left(R_{\mathrm{ct}, \text { inh }}\right)\left(R_{\mathrm{ct}, \mathrm{bl}}\right)$ are the charge transfer resistances, measured in solution with and without inhibitor.

\section{Results and discussion}

\subsection{Effect of inhibitor concentration}

To study the effect of inhibitor concentration on the inhibition efficiency, weight loss experiments were carried out in $1 \mathrm{M} \mathrm{HCl}$ solution at $303 \mathrm{~K}$ for $24 \mathrm{~h}$ immersion period. The variation of inhibition efficiency with increase in inhibitor concentration is shown in Figure 1. The extract can be seen to exhibit corrosion inhibiting effects, at all concentration used in this study, reaching a maximum inhibition efficiency of $92.89 \%$ at the optimum concentration of $1000 \mathrm{mg} / \mathrm{L}$. The values of the weight loss and percentage inhibition efficiency $(I E \%)$ obtained from weight loss method at different concentrations of MPE at $303 \mathrm{~K}$ are summarized in Table 1.

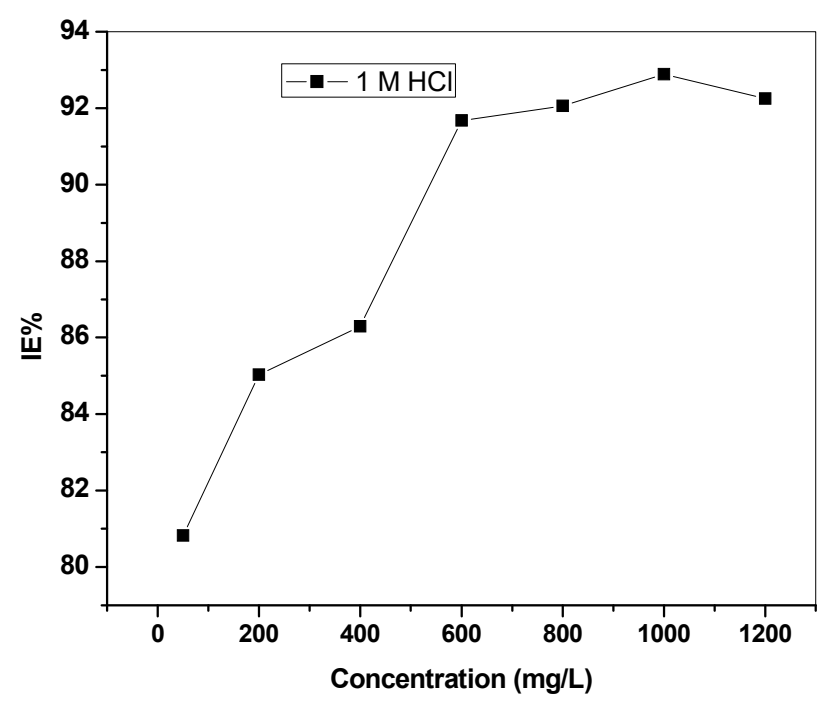

Figure 1. Effect of concentration on the inhibition efficiency of Mucuna pruriens during corrosion of mild steel in $1 \mathrm{M} \mathrm{HCl}$. 
Table 1. Corrosion parameters for mild steel in aqueous $1 \mathrm{M} \mathrm{HCl}$ in absence and presence of different concentrations of MP seed extract for 24 hours at $303 \mathrm{~K}$.

\begin{tabular}{ccc}
\hline $\begin{array}{c}\text { System } \\
\mathbf{m g}\end{array}$ & $\begin{array}{c}\text { Weight loss } \\
\mathbf{m g} / \mathbf{L}\end{array}$ & $\begin{array}{c}\text { Corrosion rate } \\
\mathbf{m g} /\left(\mathbf{c m}^{2} \cdot \mathbf{h}\right)\end{array}$ \\
\hline Blank & 159.7 & 0.216 \\
50 & 30.2 & 0.041 \\
200 & 23.6 & 0.032 \\
400 & 21.6 & 0.029 \\
600 & 13.1 & 0.019 \\
800 & 12.5 & 0.017 \\
1000 & 11.2 & 0.015 \\
1200 & 12.2 & 0.016 \\
\hline
\end{tabular}

\subsection{Effect of immersion time}

In order to assess the stability of inhibitive behaviour of crude extract on a time scale, weight loss measurements were performed in $1 \mathrm{M} \mathrm{HCl}$ in absence and containing $1000 \mathrm{mg} / \mathrm{L}$ of MPSE at $303 \mathrm{~K}$ for 7 days immersion. Inhibition efficiencies were plotted against immersion time as seen in Figure 2. This figure shows that inhibition efficiency of the extract was decreased with increasing immersion time from 1 to 7 days. The decrease in inhibition efficiency with time reflects desorption of extract components from the mild steel surface, resulting in a reduced surface coverage.

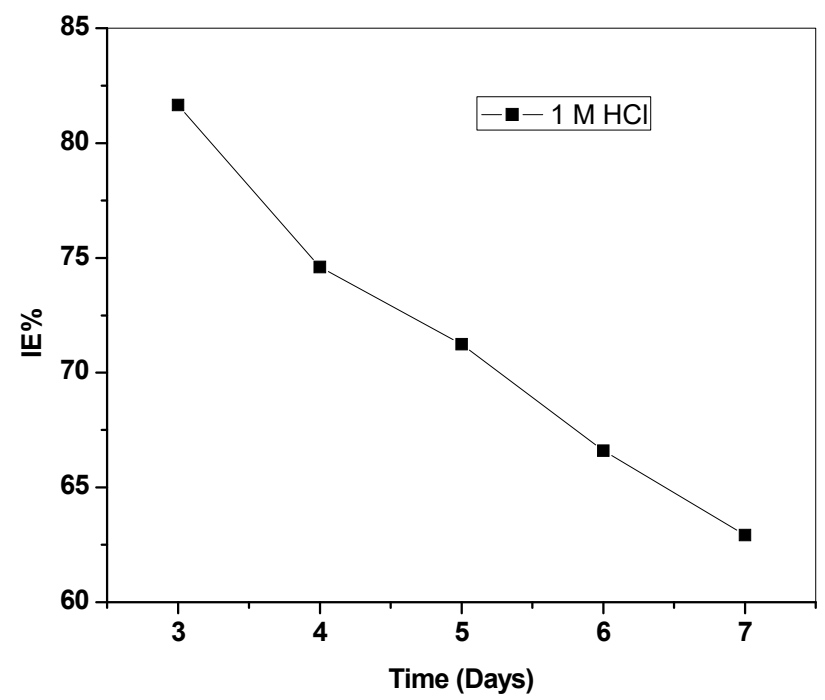

Figure 2. Effect of immersion on the IE of mild steel in $1 \mathrm{M} \mathrm{HCl} \mathrm{MPSE.}$ 


\subsection{Effect of acid concentration}

The variation of inhibition efficiency with increasing acid concentration from $1 \mathrm{M}$ to $5 \mathrm{M}$ is shown in Figure 3. It can be seen from this plot that inhibition efficiency decreases from $92 \%$ to $82 \%$ with increase in $\mathrm{HCl}$ concentration from $1 \mathrm{M}$ to $5 \mathrm{M}$. This shows that MPSE show highest inhibition efficiency in $1 \mathrm{M} \mathrm{HCl}$. The decrease in efficiency can be attributed to increased aggressiveness of solutions with increase in acid concentration.

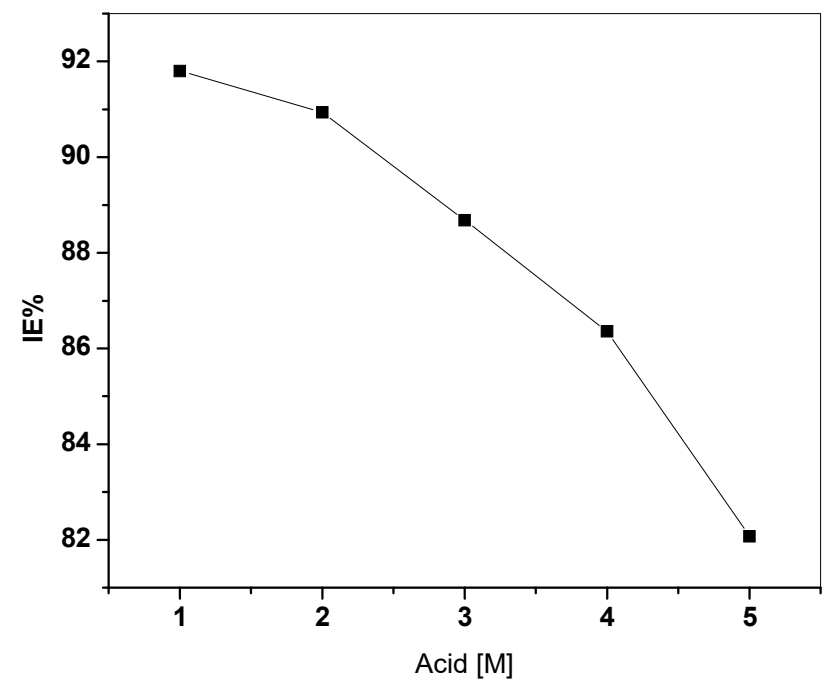

Figure 3. Effect of acid concentration on the IE\% of carbon steel by MPSE.

\subsection{Electrochemical measurements}

\subsubsection{Potentiodynamic polarization measurements}

Potentiodynamic polarization plots illustrating the effect of MPSE on the anodic and cathodic processes for mild steel corrosion in $1 \mathrm{M} \mathrm{HCl}$ solution are shown in Figure 4.

The extrapolation of Tafel straight line allows the calculation of the corrosion current density $\left(i_{\text {corr }}\right)$ and corrosion potential $\left(E_{\text {corr }}\right)$. The values of $i_{\text {corr }}, E_{\text {corr }}$, anodic and cathodic Tafel slopes $(\beta \mathrm{a}, \beta \mathrm{c})$, and inhibition efficiency $\left(I E_{\mathrm{p}} \%\right)$ are given in Table 2 . The $I E \%$ was calculated using Eq. (4). The change in $\beta \mathrm{a}$, and $\beta \mathrm{c}$ values as shown in Table 2 indicates that adsorption of MPE modified the mechanism of anodic dissolution as well as cathodic hydrogen evolution. From Figure 4, it is clear that both the cathodic and anodic reactions are inhibited, and the inhibition increases as the inhibitor concentration increased in the acid media. From Table 2, it is clear that there was no definite trend in the shift of $E_{\text {corr }}$ values, in the presence of various concentrations of MPSE in $1 \mathrm{M} \mathrm{HCl}$ solution. This result indicated that MPSE can be classified as mixed-type inhibitor in $1 \mathrm{M} \mathrm{HCl}$ solution. 


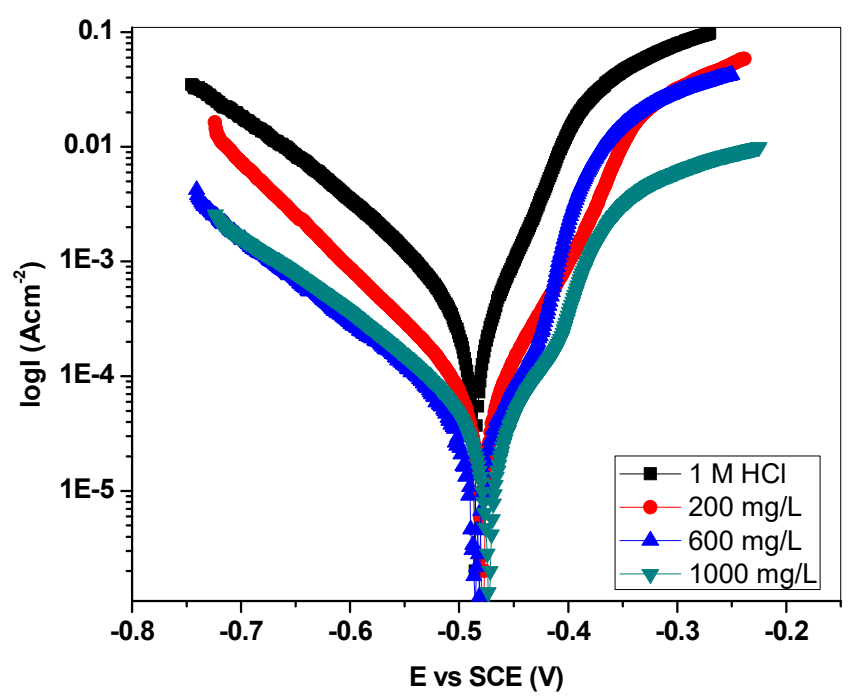

Figure 4. Potentiodynamic polarization curves of mild steel in $1 \mathrm{M} \mathrm{HCl}$ solution at $303 \mathrm{~K}$ without and with MPSE.

Table 2. Polarization parameters for mild steel corrosion in $1 \mathrm{M} \mathrm{HCl}$ solution at $303 \mathrm{~K}$ without and with MPSE.

\begin{tabular}{cccccc}
\hline System & $\begin{array}{c}\boldsymbol{\beta}_{\mathbf{c}} \\
\mathbf{m V}\end{array}$ & $\begin{array}{c}\boldsymbol{\beta}_{\mathbf{a}} \\
\mathbf{m V}\end{array}$ & $\begin{array}{c}\boldsymbol{E}_{\text {corr }} \\
\mathbf{m V}\end{array}$ & $\begin{array}{c}\boldsymbol{i}_{\text {corr }} \\
\boldsymbol{\mu A ~ \mathbf { ~ m } ^ { - 2 }}\end{array}$ & $\boldsymbol{I E}_{\mathbf{p}} \%$ \\
\hline $1.0 \mathrm{M} \mathrm{HCl}$ & 110.20 & 57.18 & -485.61 & 299.83 & \\
$200 \mathrm{mg} \mathrm{L}^{-1}$ & 101.46 & 59.36 & -480.52 & 52.81 & 82.38 \\
$600 \mathrm{mg} \mathrm{L}^{-1}$ & 103.25 & 38.40 & -479.01 & 37.53 & 87.48 \\
$1000 \mathrm{mg} \mathrm{L}^{-1}$ & 118.80 & 58.50 & -484.10 & 26.94 & 91.01 \\
\hline
\end{tabular}

\subsubsection{Electrochemical impedance spectroscopy (EIS)}

In order to obtain information about the kinetics of iron corrosion in presence of MPSE, the electrochemical process taking place was examined by electrochemical impedance spectroscopy (EIS). EIS measurements of the steel electrode in $1 \mathrm{M} \mathrm{HCl}$ solution without and with various concentrations of MPSE were obtained after $1 \mathrm{hr}$ at its open-circuit potential and the recorded EIS spectrum is shown in Figure 5. 


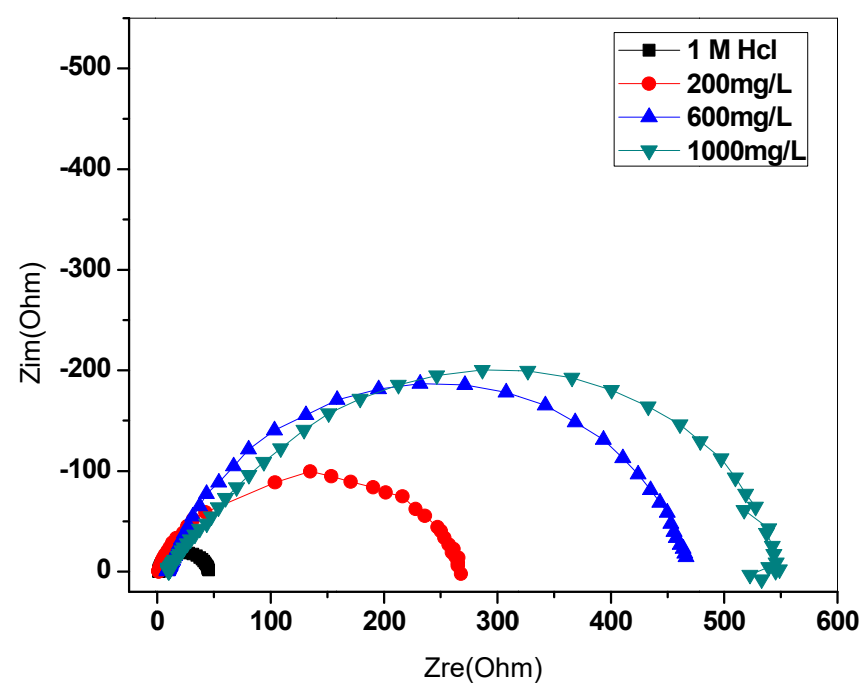

Figure 5. Electrochemical impedance spectra (Nyquist plots) of mild steel in $1 \mathrm{M} \mathrm{HCl}$ solution at $303 \mathrm{~K}$ without and with MPSE.

The impedance diagrams in the absence and presence of the extract show only one depressed capacitive loop, which is attributed to the one time constant of the charge transfer and double-layer capacitance. Deviations from a perfect circular shape indicate frequency dispersion of interfacial impedance arising from lack of homogeneity of the electrode surface due to roughness or interfacial phenomenon $[37,38]$. In these cases, the parallel network polarization resistance and double layer capacitance $\left(R_{\mathrm{ct}}-C_{\mathrm{dl}}\right)$ is usually a poor approximation especially for system where an efficient inhibitor is used. The use of a constant phase element (CPE) (Figure 6) instead of capacitance $(C)$ can be an effective way to represent the frequency dependence of non-capacitive behaviour. Excellent fit with this model was obtained for all experimental data.

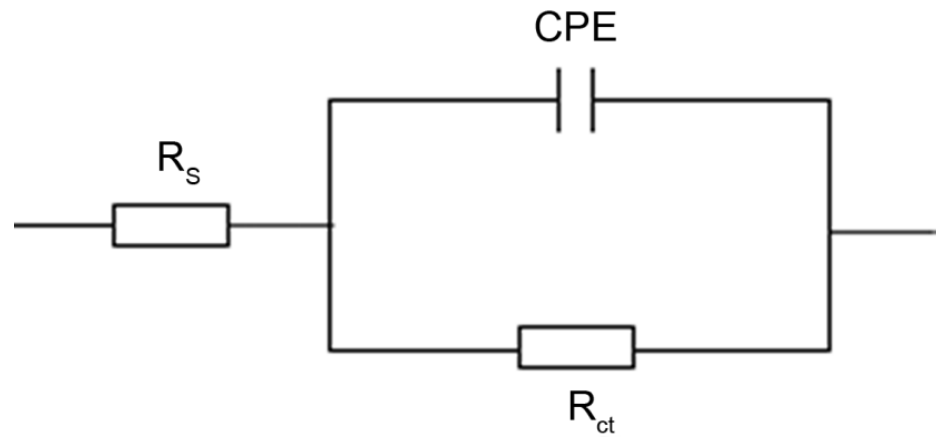

Figure 6. Equivalent circuit model represents the metal/solution interface, CPE, constant phase element; $R_{\mathrm{ct}}$, charge transfer resistance; $R_{\mathrm{s}}$, solution resistance. 
The CPE is defined by the mathematical expression [39-41]:

$$
Z_{\mathrm{CPE}}=\frac{1}{A}(j \omega)^{-n}
$$

where $Z_{\mathrm{CPE}}$, impedance of CPE; $A$ is the CPE constant; $\omega$ is the angular frequency; $j$ is the imaginary unit $(-1)^{1 / 2} ; n$, surface irregularity. The CPE, which is considered a surface irregularity of the electrode, causes a greater depression in Nyquist semicircle diagram [39], where the metal-solution interface acts as a capacitor with irregular surface. If the electrode surface is homogeneous and plane, the exponential value $(n)$ becomes equal to 1 and the metal-solution interface acts as a capacitor with regular surface, i.e. when $n=1$, $A=$ capacitance. The capacitance values of the electrical double layer were calculated according to the following equation [40-43]:

$$
C_{\mathrm{dl}}=\left(A R_{\mathrm{ct}}^{1-n}\right)^{\frac{1}{n}}
$$

Simulation of Nyquist plots with Randle's model containing constant phase element (CPE) instead of capacitance and charge transfer resistance $\left(R_{\mathrm{ct}}\right)$, showed excellent agreement with experimental data. The main parameters deduced from the analysis of Nyquist diagram for $1 \mathrm{M} \mathrm{HCl}$ without and containing MPSE are given in Table 3. On increasing MPSE concentration from $200 \mathrm{mg} / \mathrm{L}$ to $1000 \mathrm{mg} / \mathrm{L}$, the charge transfer resistance $\left(R_{\mathrm{ct}}\right)$ increased and capacitance $(A)$ decreased indicating that increasing MPSE concentration decreased corrosion rate. Decrease in the capacitance was caused by reduction in local dielectric constant and/or by increase in the thickness of the electrical double layer. This fact suggests that the inhibitor molecules acted by adsorption at the metal/solution interface $[44,45]$. On the other hand the decrease in $C_{\mathrm{dl}}$ with increase in concentration was the result of an increase in the surface coverage by the inhibitor, which led to an increase in the inhibition efficiency. The thickness of the protective layer, $\delta_{\text {org }}$, was related to $C_{\mathrm{dl}}$ by the following equation:

$$
\delta_{\text {org }}=\frac{\varepsilon_{0} \varepsilon_{\mathrm{r}}}{C_{\mathrm{dl}}},
$$

where $\varepsilon_{0}$ is the dielectric constant and $\varepsilon_{\mathrm{r}}$ is the relative dielectric constant. Since adsorption of an organic inhibitor on a metal surface involves the replacement of water molecules and other ions originally adsorbed on the surface, the smaller dielectric constant of organics compared to water as well as the increased thickness of the double layer due to inhibitor adsorption act simultaneously to reduce the interfacial capacitance [46-49]. This provides experimental evidence of adsorption of the extract organic matter on the corroding mild steel surface. 
Table 3. Impedance parameters for mild steel corrosion in $1 \mathrm{M} \mathrm{HCl}$ solution at $303 \mathrm{~K}$ without and with MPSE.

\begin{tabular}{|c|c|c|c|c|c|}
\hline System & $\begin{array}{c}\mathbf{R}_{\mathrm{s}} \\
\Omega \mathrm{cm}^{2}\end{array}$ & $\begin{array}{c}\mathbf{R}_{\mathrm{ct}} \\
\Omega \mathrm{cm}^{2}\end{array}$ & $\begin{array}{c}C_{\mathrm{dl}} \\
\mu \mathrm{F} \mathbf{c m}^{-2}\end{array}$ & $n$ & $I E_{\mathrm{E}} \%$ \\
\hline $1.0 \mathrm{M} \mathrm{HCl}$ & 1.505 & 43.65 & 72.7 & 0.714 & \\
\hline $200 \mathrm{mg} \mathrm{L}^{-1}$ & 1.186 & 243.3 & 50.7 & 0.815 & 82.10 \\
\hline $600 \mathrm{mg} \mathrm{L}^{-1}$ & 9.015 & 477.1 & 33.3 & 0.885 & 90.85 \\
\hline $1000 \mathrm{mgL}^{-1}$ & 9.651 & 545.2 & 22.1 & 0.927 & 91.01 \\
\hline
\end{tabular}

\subsection{Effect of temperature}

The effect of temperature on corrosion of mild steel in $1 \mathrm{M} \mathrm{HCl}$ acid solution in the absence and presence of 50 and $1000 \mathrm{mg} / \mathrm{L}$ MPSE at temperature range $303-333 \mathrm{~K}$, was obtained by weight loss measurements. The results obtained are given in Figure 6. Inspection of Figure 6 shows that inhibition efficiency increased with increasing solution temperature from 303 to $333 \mathrm{~K}$. This can be attributed to increased rate of adsorption of inhibitor molecules on the surface of mild steel with increasing temperature. Enhanced inhibitor adsorption at higher temperatures is an indication that some of the extract components become well adsorbed at higher temperature and so contribute more to the overall inhibiting effect.

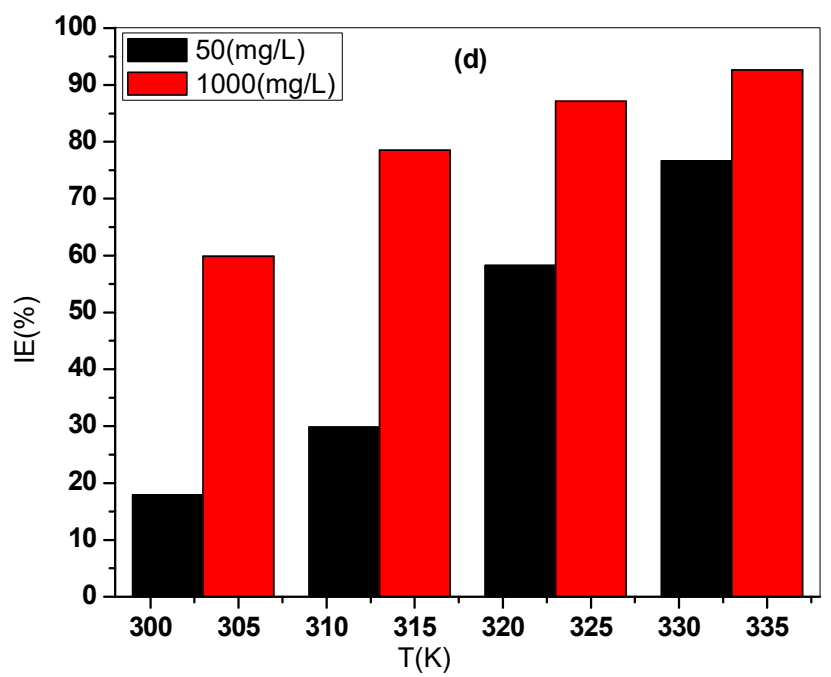

Figure 7. Variation of inhibition efficiency of MPSE with temperature during the corrosion of mild steel in $1.0 \mathrm{M} \mathrm{HCl}$. 
The dependence of corrosion rate on temperature can be expressed by the Arrhenius equation [1]:

$$
\log C_{R}=\frac{-E_{a}}{2.303 R T}+A,
$$

where $E_{\mathrm{a}}$ is the apparent effective activation energy, $R$ is the general gas constant and $A$ is the Arrhenius pre-exponential factor. A plot of $\log C_{\mathrm{R}} v s .1 / \mathrm{T}$ gave a straight line as shown in Figure $8 \mathrm{a}$ with a slope of $-E_{\mathrm{a}} / 2.303 R$.
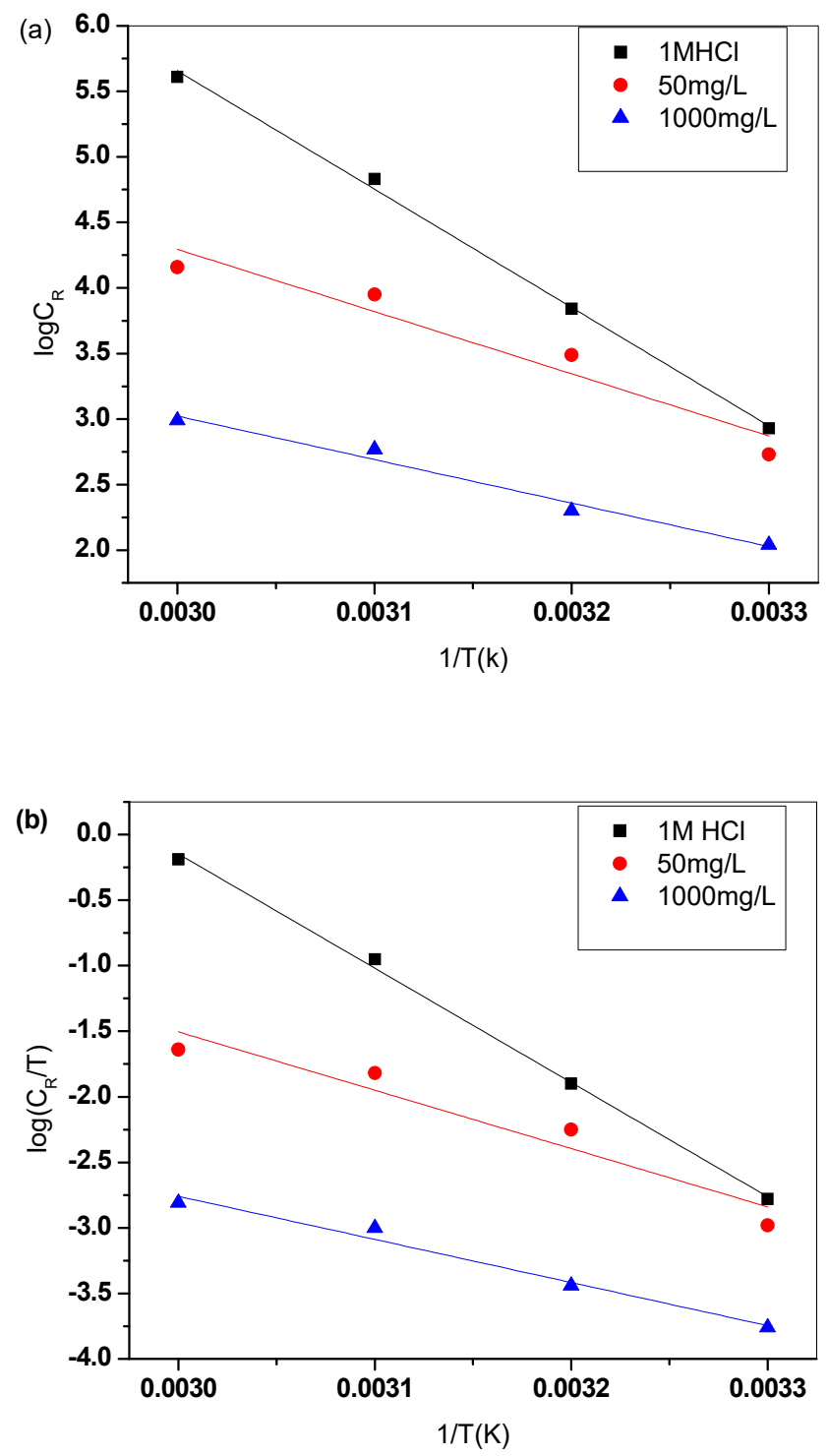

Figure 8. Arrhenius plots of: (a) $\log C_{\mathrm{R}} v s .1 / T ;(b) \log \left(C_{\mathrm{R}} / T\right) v s .1 / T$ for the mild steel in $1.0 \mathrm{M} \mathrm{HCl}$ solution in the absence and presence of MPSE. 
An alternative formulation of Arrhenius equation is:

$$
C_{R}=\frac{R T}{N h} \exp \left(\frac{\Delta S^{*}}{R}\right) \exp \left(\frac{-\Delta H^{*}}{R T}\right),
$$

where $h$ is Plank's constant, $N$ is Avogadro's number, $S^{*}$ the entropy of activation and $H^{*}$ is the enthalpy of activation. A plot of $\log \left(C_{\mathrm{R}} / T\right) v s .1 / T$ gave a straight line with a slope of $-H^{*} / 2.303 R$ and an intercept of $\log (R / N h)+S^{*} / 2.303 R$ (Figure $8 \mathrm{~b}$ ), from which the values of $S^{*}$ and $H^{*}$ were calculated and listed in Table 4. The data in Table 4 reveal that the values of thermodynamic activation functions $\left(E_{\mathrm{a}}\right.$ and $\left.\Delta H^{*}\right)$ for corrosion of the mild steel in $1 \mathrm{M} \mathrm{HCl}$ solution in the presence of the inhibitor are lower than those in the free acid solution. Lower values of $E_{\mathrm{a}}$ and $\Delta H^{*}$ in the presence of inhibitor indicate that the energy barrier for the corrosion reaction was lowered in presence of MPSE.

This phenomenon may be attributed to the change in mechanism of the corrosion process in the presence of adsorbed inhibitor molecules which often interpreted as chemisorption of the inhibitor involving charge transfer from the molecules of MPSE to the mild steel surface [3]. This conclusion is corroborated by the increase in inhibition efficiency with increasing temperature. The positive signs of enthalpies $\left(H^{*}\right)$ obtained reflects the endothermic nature of dissolution process. The shift towards negative value of entropies $\left(S^{*}\right)$ at the optimum concentration imply that the activated complex in the rate determining step represents association rather than dissociation, meaning that disordering decreases on going from reactants to the activated complex [50].

Table 4. Values of activation energy, $E_{\mathrm{a}}(\mathrm{kJ} / \mathrm{mol})$; enthalpy, $\Delta H(\mathrm{~kJ} / \mathrm{mol})$ and entropy, $\Delta S(\mathrm{~J} / \mathrm{mol})$ for corrosion of mild steel in $1.0 \mathrm{M} \mathrm{HCl}$ in absence and presence of MPSE.

\begin{tabular}{cccc}
\hline $\begin{array}{c}\text { System } \\
\mathbf{m g} / \mathbf{L}\end{array}$ & $\begin{array}{c}\text { Activation energy } \boldsymbol{E}_{\mathbf{a}} \\
\mathbf{k J} / \mathbf{m o l}\end{array}$ & $\begin{array}{c}\text { Enthalpy } \Delta \boldsymbol{H} \\
\mathbf{k J} / \mathbf{m o l}\end{array}$ & $\begin{array}{c}\text { Entropy } \Delta \boldsymbol{S} \\
\mathbf{J} /(\mathbf{m o l} \cdot \mathbf{K})\end{array}$ \\
\hline Blank & 116.32 & 113.7 & 110.93 \\
50 & 39.49 & 36.99 & 109.93 \\
1000 & 27.60 & 27.35 & -13.82 \\
\hline
\end{tabular}

\subsection{Mechanism of inhibition}

Corrosion inhibition of mild steel in $1 \mathrm{M} \mathrm{HCl}$ in presence of MPSE can be explained on the basis of molecular adsorption [16]. MPSE inhibits the corrosion of mild steel by controlling both the anodic and cathodic reactions. From data presented in Table 2 it is clear that MPSE inhibits the corrosion of mild steel by blocking the anodic and cathodic sites. The main constituents of MPSE are L-dopa, Glutathione, Gallic acid and Betasitosterol whose structures are given in Figure 9 having a number of amine $(-\mathrm{NH})$ and hydroxyl $(-\mathrm{OH})$ groups and a number of aromatic rings. These organic molecules gets 
adsorption on the metal surface forming a protective layer and hence the anti-corrosive behaviour [51]. The extract components may adsorb on the metal/acid solution interface by one and/or more of the following ways: $(i)$ electrostatic interaction of protonated molecules with already adsorbed chloride ions, (ii) donor-acceptor interactions between the $\pi$ electrons of aromatic ring and vacant d-orbital of surface iron atoms, (iii) interaction between unshared electron pairs of hetero atoms and vacant d-orbital of iron surface atoms.<smiles>NC(CCC(=O)NC(CS)C(=O)NCC(=O)O)C(=O)O</smiles>

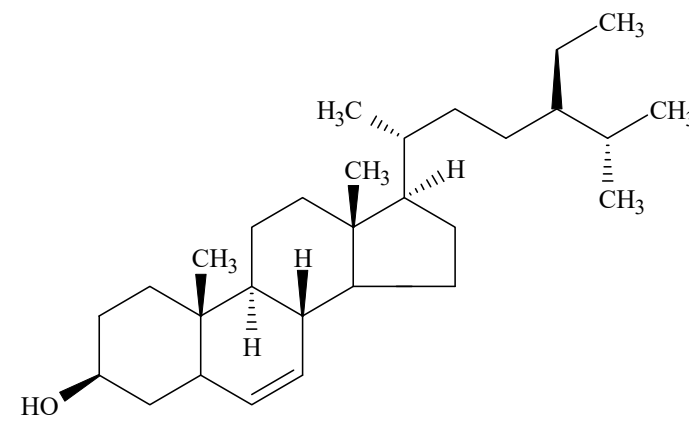

Beta sitosterol<smiles>O=C(O)c1cc(O)c(O)c(O)c1</smiles>

Gallic acid

Figure 9. Chemical structure of the major active components of MPSE.

\section{Conclusion}

Test results show that MPSE is an efficient inhibitor for mild steel corrosion in $1 \mathrm{M} \mathrm{HCl}$ solution. The inhibition efficiencies increased with increase in the inhibitor concentration, which reveals the inhibitive actions of MPSE is mainly due to the adsorption on the electrode surface. Potentiodynamic polarization measurements reveal that MPSE acts as a mixed type inhibitor but effect on the anodic reactions is more predominant. EIS measurement reveals that charge transfer increases with increase in concentration of MPSE, indicating that the inhibition increases with increase in concentrations. The values of the free energy for the adsorption process indicate that chemisorption is involved in the adsorption of the studied fatty acid amide surfactants on the mild steel surface. The data from weight-loss, polarization and impedance techniques are in reasonable good agreement.

\section{Acknowledgement}

The authors wish to acknowledge the Electrochemical and Material Science Unit (EMRU), Department of Chemistry, FUTO, for providing the facilities for the work. 


\section{References}

1. A. Singh, V.K. Singh and M.A. Quraishi, Rasayan J. Chem., 2010, 3, no. 4, 811.

2. A.K. Satapathy, G. Gunasekaran, S.C. Sahoo, K. Amit and P.V. Rodrigues, Corros. Sci., 2009, 51, 2848.

3. F.S. De Souza and A. Spinelli, Corros. Sci., 2009, 51, 642.

4. L.E. Tsygankova, M.N. Esina, V.I. Vigdorovich and N.V. Shel, Int. J. Corros. Scale Inhib., 2014, 3, no. 1, 48. doi: 10.17675/2305-6894-2014-3-1-048-058

5. M.A. Quraishi and D. Jamal, J. Appl. Electrochem., 2002, 32, 425.

6. M. Elayyachy, A. El Idrissi and B. Hammouti, Corros. Sci., 2006, 48, 2470.

7. K.C. Emregul and M. Hayvali, Corros. Sci., 2006, 48, 797.

8. B. Mernari, H. Elattari, M. Traisnel, F. Bentiss and M. Lagrenee, Corros. Sci., 1998, 40, 391.

9. L. Wang, Corros. Sci., 2001, 43, 2281.

10. M.E. Azhar, M. Mernari, M. Traisnel, F. Bentiss and M. Lagrenee, Corros. Sci., 2001, 43, 2229.

11. P.R. Roberge, Corrosion Inhibitors, Handbook of Corrosion Engineering, 1999, McGraw-Hill, New York.

12. G. Trabanelli, in Corrosion Mechanisms, Ed. F. Mansfeld, Marcel Dekkar, Inc., New York, 1987, p. 119.

13. M. Lebrini, M. Traisnel, M. Lagrenee, B. Mernari and F. Bentiss, Corros. Sci., 2008, 50, 473.

14. A. Lecante, F. Robert, P.A. Blandinieres and C. Roos, Curr. Appl. Phys., 2011, 11, 714.

15. R.M.H. Lemmens and N. Wulijarni-Soetjipto, Plant Resources of South-East Asia, 1991, No. 3: Dye and Tannin-Producing Plants, Pudoc Wageningen.

16. S. Muthumanickam, B. Jeyaprabha, R. Karthik, A. Elangovan1 and P. Prakash, Int. J. Corros. Scale Inhib., 2015, 4, no. 4, 365. doi: 10.17675/2305-6894-2015-4-4-6

17. P.B. Raja and M.G. Sethuraman, Mater. Lett., 2008, 62, 113.

18. A.I. Ikeuba, P.C. Okafor, U.J. Ekpe and E.E. Ebenso, Int. J. Electrochem. Sci., 2013, 8, no. 5,7455 .

19. A.Y. El-Etre, Appl. Surf. Sci., 2006, 252, 8521.

20. E.E. Oguzie, K.I. Iyeh and A.I. Onuchukwu, Bull. Electrochem., 2006, 22, 63.

21. J.C. Da Rocha, J.A. Da Cumha Ponciano Gomes and E. D'Elia, Corros. Sci., 2010, 52, no. $7,2341$.

22. A. Singh, V.K. Singh and A.M. Quraishi, Arabian J. Sci. Eng., 2012, 38, no. 1, 85.

23. J.I. Gopal, S.K. Shukla, P. Dwivedi, S. Sundaram, E.E. Ebenso and R. Prakash, Int. J. Electrochem. Sci., 2012, 7, 12146.

24. S. Umoren, I.B. Obot, G. Gasem, and N.A. Odewunmi, J. Dispers. Sci. Technol., 2015, 36, no. 6, 789 .

25. N. Gunavathy and S.C. Murugavel, Asian J. Chem., 2013, 25, no. 5, 2483. 
26. S. Ananth-Kumar, A. Sankar, M. Vijayan and S. Rameshkumar, IOSR J. Eng., 2013, 3, no. $8,10$.

27. P. Thilagavathy and R. Saratha, IOSR J. Appl. Chem., 2015, 8, no. 1, 30.

28. E.E. Oguzie, Port. Electrochim. Acta, 2008, 26, no. 3, 303.

29. B. Omar, S. Chaouki and R. Salghi, Res. Chem. Intermed., 2014, 40, 259. doi: 10.1007/s11164-012-0960-8

30. L. Li, X. Zhang, J. Lei, J. He, S. Zhang and F. Pan, Corros. Sci., 2012, 63, 82.

31. C.O. Akalezi and E.E. Oguzie, Int. J. Ind. Chem., 2016, 7, 81. doi: 10.1007/s40090015-0057-5

32. A. Ostovari, S.M. Hoseinieh, M. Peikari, S.R. Shadizadeh and S.J. Hashemi, Corros. Sci., 2009, 51, 1935.

33. P. Kuma and S. Saha, J. Pharmacogn. Phytochem., 2013, 2, no. 1, 306.

34. C.P. Khare, Encyclopedia of Indian medicinal plants, Springer Verlag, Berlin, Heidelberg, 2004.

35. L. Mishra and H. Wagne, Indian J. Chem., 2006, 45B, 801.

36. Quality standards of Indian medicinal plants, Indian council of medical research, 2005, $1,136$.

37. H.P. Sachin, M.H. Moinuddin Khan, S. Raghavendra and N.S. Bhujangaiah, The Open Electrochem. J., 2009, 1, 15.

38. M. Ozcan, R. Solmaz, G. Kardas, I. Dehri, Coll. Surf. A: Physicochem. Eng. Aspects, $2008,325,57$.

39. J.R. Macdonald, Impedance Spectroscopy, 1987, John Wiley and Sons.

40. J. Cruz, T. Pandiyan and E.G. Ochoa, J. Electroanal. Chem., 2005, 583, 8.

41. A. Popova, M. Christov, A. Vasilev and Chr. Girginov, Int. J. Corros. Scale Inhib., 2015, 4, no. 4, 382. doi: 10.17675/2305-6894-2015-4-4-7

42. D.A. Lopez, S.N. Simison and S.R. de Sanchez, Corros. Sci., 2005, 47, 735.

43. D. Seifzadeh and Z. Rajabalizadeh, Surf. Coat. Technol., 2013, 128, 119.

44. H.A. Sorkhabi, B. Shaabani and D. Seifzadeh, Electrochim. Acta, 2005, 50, 3446.

45. M. Lebrini, F. Robert, A. Lecante and C. Roos, Corros. Sci., 2010, 53, no. $2,687$.

46. K.F. Khaled and S.S. Abdel-Rehi, Arabian J. Chem., 2011, 4, 397.

47. J.K. Sam, J.K. Mohammad and J. Abraham, Bull. Mater. Sci., 2011, 34, no. 6, 1245.

48. M.A. Muralidharan, M.A. Quraishi and S.K.V. Iyer, Corros. Sci., 1991, 37, no. 11, 1739 .

49. J.M.O. Bockris and A.K.N. Reddy, Modern Electrochemistry, Plenum Press, New York, 1997, pp. 1267-1272.

50. H.M. Bhajiwala and R.T. Vashi, Bull. Electrochem., 2000, 17, 441.

51. N. Nair Rekha, I.K. Sashi Sharma, P.S. Sharma and A.S. Verma, Rasyan J. Chem., 2010,3 , no. $4,783$. 